\title{
Postmodernist Narrative: In Search of an Alternative.
}

\author{
Brian Crews \\ Universidad de Sevilla
}

\begin{abstract}
The development of the novel form is an exploration of the possibilities for realistic representation which is increasingly informed by an understanding that distortion and fabrication are inevitable consequences of the mediating process of narrative. The search for alternatives to conventional modes of representation as a way of defamiliarizing this state of affairs draws attention to the fact that the ordered human constructs that compose knowledge are fictitious systems that inevitably invade reality. A number of contemporary authors, through a variety of strategies emphasize the inevitable distortion involved in representation. The world is always transposed, reality is always framed in terms of the conventions we know and becomes an unfamiliar absence continually deferred by the fictitious construct we call knowledge. Martin Amis, Angela Carter and Ian McEwan are just a few of the authors who question existing realisms and posit alternatives but in the knowledge that reality is always other than what we make it.
\end{abstract}

Postmodernism is really all about forms of representation and the ways in which we depict and come to terms with what we call reality (no matter the medium involved); or even if we can talk about reality or truth at all. J.F. Lyotard suggests that all forms of representation rely upon narrative in order to validate themselves, and it could be said that all knowledge is primarily narrative as, no matter their medium, all artistic and cultural representations require some metanarrative to explain, validate or justify them (1984: 7). This in itself suggests a clear distinction between reality and our knowledge of it and we can trace a constantly changing awareness regarding the relationship between forms of representation and the developing reality they are supposed to depict. Frederic Jameson explains this in terms of the history of the sign between the eighteenth century and the present day: from the realistic reification of the sign we have moved through the modernist 
rupture of the relationship between the sign and its referent (although the belief in some relation still remained), to the present day "pure and random play of signifiers which we call postmodernism" (1987: 222). It is curious to note that the period described by Jameson coincides with the beginnings and the development of the English novel, and we might say that the novel not only mirrors this changing relationship between signifier and signified, but has continually been preoccupied with the problem of representation and has shown a constant desire to be realistic in this regard throughout its history. In fact, the novel has developed precisely because of its efforts to become more realistic.

Discussions about postmodernism often centre on narrative, and a point that ought to be made is that we can posit an analogous relationship between novel and postmodernism. It is much more than that many instances of postmodernism occur in the novel form. It is more than a coincidence, and the basis of this relationship rests on the fact that both the novel and postmodernism can be considered as oppositional discourse, as both involve a relationship, or a variety of relationships of antagonism or opposition towards already existing forms of representation which are considered and consider themselves to be valid, authentic, authoritative, or even realistic. When we consider the postmodernist novel in this light, we can suggest that it exists as the result of developments in the novel itself, or is made possible by its nature, although this has been informed by ideological change too. Moreover, as oppositional discourse, many features that are considered to be postmodernist in narrative are already to be found in the novel form. We could say that the postmodernist novel takes advantage of possibilities in the novel form itself to push it in new and different directions, although it still remains a novel and bears some relation with its past. In this sense it is the continuation of a developing mode, and there are a number of features that allow us to suggest this.

From its beginnings, the novel appears to react to other, particularly literary forms of narrative, and, since then, has always been open to the assimilation of a great variety of modes of discourse. The novel is, therefore, a hybrid, open genre which can take advantage of already existing forms of representation, and, at times, does so critically and questioningly. Even during its realistic phase, it can be considered as exploring its own possibilities for representation in order to persuade itself, as well as the reader, of its verisimilitude. We have been told rightly not to consider the realistic novel as a paradigm, but as a stage of development in a self-reflexive tradition which has always informed the novel (Hutcheon 1984: 38). In this sense, it has always been innovative, and a broad variety of distinct cultural codes and forms of expression, both literary and non-literary, continually come into contact with each other (Holquist \& Reed 416). Not only that, but if, as Malcolm Bradbury has stated, each novel is a unique set of variables (1973: 289), this can be considered as the particular use of already existing possibilities, linguistic and narrative, where the choices made within different categories of discourse can produce a variety of effects and are, in fact, determined by and suggestive of distinct attitudes towards existing realisms. It is possible to isolate more or less conventional tendencies in the novel, but its development can almost always be seen in terms of its particular use of available materials, although it should also be stated that the novel steals, borrows and cobbles bits on from other media that are not necessarily literary in its attempts to contain reality (Johnson 1973: 16-17). The postmodernist novel is innovative in the same way. 
Speaking of other media, it is worth considering the emphasis on the visual aspect in the novel even until modernism and beyond:

... by an initial rite the writer must first transform the real into a painted object (a framed one); after which he can unhook this object, pull it out of his painting, in a word de-pict it. ... All of this opens up a double problem. First of all, whence and when began this preeminence of the pictorial code in literary mimesis? Why has it disappeared? Why did writers' dream of painting die? (Barthes $S / Z$ in Thiher 1 )

This dream of visual representation may have come to an end because of the appearance of visual media (cinema and television) which could do the job much better, which left the novel to get on with what it could do best (see Johnson 1973). At any rate, what is clear is that mimesis or realism in narrative has often been associated with this kind of visual element (landscape, setting, physical appearance and so on), which has been influential in the way in which cinema, television and even video have gradually become an influence on certain narrative texts. As we suggested, this is so because the novel has always been a kind of investigation of the possibilities for representation, as Robert Alter points out:

The realistic enterprise has been enormously complicated and qualified by the writer's awareness that fictions are never real things, that literary realism is a tantalising contradiction in terms. If modern philosophy can be said to begin with Decartes's methodological skepticism, his making ontology essentially problematic, a whole tradition of the novel as the paradigmatically modern narrative genre, is informed by that same critical philosophical awareness, beginning about half a century before Decartes with Cervantes. Ontological critique, moreover, is carried on typically not as discursive exposition but as a critical exploration through the manipulation of the very form that purports to represent reality. $(1975: \mathrm{x})$

The idea of ontological critique is usually associated with the postmodern and metafiction, but it is not exclusive to it. The novel has always explored its possibilities although a growing awareness of the nature of the medium, the act of mediation and the inevitability of manipulation are fundamental in what we see as its development. In fact, we could say that the history of the novel is a history of its attempts to avoid, dissimulate, and later emphasize mediation and manipulation. But this is only one aspect of the question:

Continually demanding a renewal of its realism, the novel accentuates the ambiguities of literary representation. On the one hand, the objects represented (roads, coins, furniture, bodies, persons) are given an autonomy from the dominant semantic field of the narrative; they signify, but on a different level or plane. On the other hand, the medium of representation (point of view, narrative voice, prose style, the printed page) calls attention to its intermediary role; it dramatizes itself as the bearer of significance. The strategies of such an accentuation are diverse, but the novel is a special use of what semiotics calls a staggered system. It is in this sense, in its radical displacements of 
signifier and signified, that Tristram Shandy is the most typical novel of world literature, as Shklovsky claimed. In its cultivation of imbalance, it is the staggered system par excellence. (Holquist and Reed 418)

Once the novelist's dream of painting dies, it is the self-conscious awareness of the intermediary role that becomes uppermost in much narrative, which begins to investigate the process of mediation and even questions the possibility of representation: what can we signify or refer to; and the novel has developed in this sense also, once emphasising the world beyond the text, or, more recently, suggesting that we can only refer to other signs and other texts.

The realistic novel as it is considered traditionally attempted to persuade the reader of its truthfulness, often involving "the representation of experience in a manner which approximates clearly to the description of similar experience in non-literary texts of the same culture" (Lodge 1977: 25). This reference to what is the possibility of adapting existing modes of representation to fictional narrative draws attention yet again to the question of mediation, and it should be obvious that this preoccupation stems from the fact that there is no possibility of unmediated reality in narrative, or even elsewhere for that matter. Something must always get in the way of it and this is what has led some critics to contrast narrative with drama and to consider narrative as somehow less realistic. Obviously, there can be no such thing as a truly dramatic narrative text, although we may be relatively unaware of the presence of the narrator, the existence of a frame, or even of the act of narration itself. Although we may be persuaded to forget about the narrator, the function of narration always takes place. Novelists have always known this although some critics have been slower to appreciate it, but it might also be argued that the novel is more realistic for that very reason. Kate Friedemann argues:

"the narrator" is the one who evaluates, who is sensitively aware, who observes. He symbolizes the epistemological view, familiar to us since Kant that we do not apprehend the world in itself, but rather as it has passed through the medium of an observing mind. In perception, the mind separates the factual world into subject and object. (In Stanzel 4)

It is because of this that the novel is so preoccupied with what have become postmodernist concerns, but these have always been the concerns of the novel. The fact that the observer always changes what he observes and that there is no objective reality is what the history of the novel is about. Genette makes it clear that narrative is not a "weakened, attenuated mode of literary representation" (1982: 130), but is more mimetic than drama itself precisely because the narrator does embody the epistemological view. The developing awareness of this state of affairs has been reflected in the development of the novel towards postmodernism.

In the light of what has been said, the postmodernist tendency towards metafiction in some cases can be considered as "an exaggeration of the tensions and oppositions inherent in all novels: of frame and frame break, of technique and counter-technique, of construction and deconstruction of illusion" (Waugh 14). Let us say that the novel 
continues to do what it has always done although we also find "shifts of emphasis, restructurings and evasions ... to accommodate and make tolerable contemporary reality and the modern experience in general" (Stevenson 1992: 15). What Stevenson says here about modernism is true of the novel at many stages of its development as it compensates for, reflects or avoids the changes that take place around us. The tendency to question existing attitudes towards realism has always informed the development that has taken place in the novel, and the same applies to recent developments in postmodernist narrative. As oppositional discourse, the novel exists in a relation of opposition to other modes, traditions and conventions, as well as to alternative considerations of realism, even offering these alternatives itself. While the novel is still sometimes guilty of compounding the realistic fallacy, it has also developed in reaction to it, which is the same as saying that the postmodernist novel reacts in the light of the fallacies of accepted realism, as it is perturbed by the ready acceptance of convention and the conventional. For these reasons, the novel is anti-traditional, although history has continually naturalized its changes and innovations regarding forms of representation. But the changes continue, particularly with regard to attitudes towards reality and realism, which continually leads the novel in search of alternative modes of presentation in its attempts to be more realistic.

The way in which other modes have been assimilated into the novel suggests that its attempts at realism oppose literature after a fashion that postmodernism continues. Michael Holquist and Walter Reed see the novel as being "essentially tied to realism whenever realism is conceived as more real than literature since the novel always operates in reaction to literature" (1988: 417). This is true of many novels which appear after modernism, which also operate in reaction to other forms of representation within our culture, in such a way that the novel, as literature, can now be conceived as attempting to be more realistic or offering an alternative not only to literary modes of representation, but even to those non-literary forms that purport to represent reality in contemporary culture. Holquist and Reed go on:

The so-called realism of the novel is an open-ended series of realisms . . in which narrative codes that are traditional or conventional in the contemporary institution of literature confront narrative codes that are perceived as extra-literary. ... No single code is given its full authority and the claim of each is contested in the particular resolution of the text. (418)

By all accounts, they could be talking about the postmodernist novel here, where the idea of installing and contesting conventions as well as offering alternatives to the authoritative text can be considered fairly accepted features of this kind (Hutcheon 1989: 1-2). It would seem that the novel has always done this in an attempt to renew its realism as it moves from traditional realistic narrative, through modernism to postmodernism, although, as we suggested, there has always been a tradition, perhaps beginning with Sterne, if not Cervantes, where the novel has drawn attention to the ambiguities and medium of representation.

Something that might lead us to a better understanding of the analogous relation between postmodernism and novel is what Shklovsky says about the history of narrative. 
He sees it as a continual making strange or defamiliarization, which has brought about the constant renewal of the form (Lemon \& Reis 1965: 57). Bakhtin shares a similar view, but sees narrative as defamiliarizing different ways of talking about the world (1981: 5-38). In some recent fiction, both the world and ways of talking about it are defamiliarized, and the tendency is not simply to experiment with ways of representing reality, but that reality itself is shown to be unfamiliar.

Bakhtin draws attention to the fact that the novel has been informed by a different concept of time, where the openended present becomes the focus. This is opposed to the sense of wholeness or completeness afforded by epic or other literary kinds. We could say that the novel deals with contemporary history, although we ought to consider that concept as referring to something ongoing, a reality which continually recedes in the present. Bakhtin tells us that the novel

developed as a genre that had a new way of conceptualizing time. The absolute past tradition, hierarchical distance played no role in the formation of the novel as a genre. ... The novel took shape precisely at the point when epic distance was disintegrating . .. when the object of artistic representation was being degraded to the level of a contemporary reality that was inconclusive and fluid. (1981: 38)

This direct contact with present-day reality and the lack of any notion of an absolute past make the novel the novel, as, with postmodernism, it returns once more to a sense of inconclusiveness and incompleteness in an ever-receding and ever-changing present which is much more radically part of our contemporary awareness. This contact with the present, its contemporary nature, is what allows the novel to develop with greater freedom, but curiously becomes of increasing thematic significance as the novel develops towards postmodernism, where in a post-Einsteinian world we cannot help but be influenced by a new way of conceptualizing time.

In the visual arts we have seen how modernist tendencies have led to an obvious defamiliarization of the object (making it sometimes unrecognizable), or to surrealism which suggests a dream or invisible reality which relies often on the modernist devices of myth or symbol in order to be understood. This was so because the conventional representations of realism failed to consider reality at all, ignoring the fact that the conventional forms they used represented a conventional or framed world, subject to the distortion inevitably brought about by the process of mediation. This would later be called the realistic fallacy. The introduction of alternative modes of composition which were accompanied by even greater distortion effectively drew attention to the conventions themselves which had been ignored. However, this has always been a preoccupation in the novel as "[novels] are always aware of the opacity of cultural categories which to realists look like windows (realists forget they are looking through something)" (Holquist \& Reed 417). But the novel seems to have become preoccupied with the difficulty of continuing to defamiliarize reality, and this, not only in the novel, but in film, photography, and other areas, for postmodernism is a major preoccupation. Once everything becomes all too familiar one possible reaction is this: 
In reply to an enquiry, it was explained that a satisfactory novel should be a self-evident sham to which the reader could regulate at will his degree of credulity. ... Characters should be interchangable as between one book and another. The entire corpus of existing literature should be regarded as a limbo from which discerning authors could draw their characters as required, creating only when they failed to find a suitable existing puppet. The modern novel should be largely a work of reference. Most authors spend their time saying what has been said before - usually said much better. (O'Brien 1967: 25)

In this form of response, the novel becomes a commentary on its predecessors, on the fictitious constructs and processes of representation that are available to the writer, and by using or playing with what is already familiar to some of us, Flann O'Brien defamiliarizes a number of traditional modes of representation. What strikes us at first as a break with tradition (and it is in a sense), turns out to be a more extreme manifestation of the novel as oppositional discourse, where the relation between the contemporary narrative and its literary past, because of the parodic nature of the work, can clearly be considered as such. Another postmodernist author, this time from the $60 \mathrm{~s}$, follows O'Brien's line, but in a less playful manner:

The novelist cannot legitimately or successfully embody present day reality in exhausted forms. . . . Present day reality is changing rapidly, it always has done, but for each generation it appears to be speeding up. Novelists have to evolve (by inventing, borrowing, stealing or cobbling from other media) forms which will more or less contain an everchanging reality. (Johnson 1973: 17)

The curious thing about Johnson's work, however, is the way in which he deliberately courts failure. He builds his house of fiction in order to knock it down; goes to great lengths to create a sense of verisimilitude and then, in an arbitrary fashion, refutes it, always drawing attention to the inevitable distortion and manipulation involved in any narrative. In his novels he installs and contests a wide range of existing modes of representation, but his playful inventiveness involves a rather melancholy irony: each strategy which attempts to bring us closer to reality draws attention to itself as just that, and the process of mediation becomes even more apparent. In the quotation, by alluding to "borrowing, stealing and cobbling," Johnson suggests that for the most part the contemporary author cannot avoid alluding to existing forms, underlining the fact that our understanding of reality is tied to conventional models of representation. Invention, to recall O'Brien's comment, is an alternative to be made use of only when no appropriate source is found. So, in order to develop with his times and to keep up with the everchanging nature of contemporary reality, the author's alternatives, or two of them, are to annotate existing sources or to invent, borrow and steal; but the novel, up to a point, has always done this anyway, and it is significant to note that Johnson refers here to evolution and not a break with the past. The postmodernist novel remains oppositional discourse, but these attitudes suggest a changing attitude towards the novel form, or a greater awareness of the nature of narrative representation in general. How narratives are composed and constructed and their relation with reality becomes a feature of the contemporary novel 
leading to a number of more particular concerns that achieve greater emphasis in more recent times.

Among postmodernists, the tendency is to see all forms of representation as limiting and distorting our visions of reality, so that postmodernism is essentially subversive in its desire to make this inevitable distortion of reality and experience clear. Rather than considering reality as something representable, it is now seen as a fictional construct dependent on the ideologies implicit in existent modes of representation. So, the question becomes whether we are able to conceive of reality at all, or if all we know and recognize are the forms, traditions and conventions of a number of already existing realisms. We can say that postmodernism represents an extreme stage of thought in the development of attitudes towards the relation between reality and representation. Nowadays, there are still traditional/realistic manifestations or representations of life and experience on the market, but these have begun to be considered as obvious fictions, products of a society that trades in images or simulacra, where truth is just one more marketable commodity. Fictions purporting to be the truth compete with one another, and reality recedes. In a contemporary situation where it seems that we have lost sight of the truth and even of reality itself, what we find in some postmodernist narratives is a tendency to produce fragmentary, obviously fictitious constructs lacking in depth or significance. The refusal to signify or the failure to signify, admissions of limitations and of ignorance have substituted the significant referential text. In the same way, postmodernism tends to be subversive in the way it rejects the conventions that give authority to the text, often presenting itself in hybrid forms (like the novel itself) that self-critically draw attention to their own limitations or inability to represent anything.

As Matei Calinescu suggests, it is now admitted that we cannot construct reality, only possible worlds (1987: 203), possible in accordance with the modes or conventions that are used. We construct conventional worlds, not real worlds, because convention and consensus are also necessary in order to come to terms with even possibility. Something to consider in this respect is that consensus suggests, or might suggest, at least nowadays and rather paradoxically, a kind of reluctant although voluntary acceptance. In his story "Tlön, Uqbar, Orbis Tertius," Borges tells an anecdote about Hume remarking that Berkeley's arguments were irreproachable but that they did not inspire the least conviction (21): we assent to the organized system but it does not have to be true. When alternatives are found to existing convention then we have an alternative system, an alternative possibility, an alternative reality, an alternative world, but it does not necessarily have to be true. It is this awareness of what has always been the case that informs much contemporary narrative and Borges anticipates the reaction of some novelists in some of his stories which become commentaries and annotations of works which, then, did not exist. As he says in the prologue to his Ficciones, "a better procedure is to pretend that these books already exist and offer a summary, a commentary" of texts that offer alternative systems to those that govern the fictional worlds we inhabit (1985: 12; here and elsewhere Borges is freely translated).

Borges shows us that we can and do build worlds, something which is possible due to the ontology of language and discourse. It has been said that "the creation of systems that order a world [that in turn create a world] is a gratuitous (but necessary) form of play" 
(Thiher 160) and this is what Borges draws attention to in a narrative like "Tlön, Uqbar, Orbis Tertius." Language, whose rules are arbitrary, if the system is consistent, constitutes what is real at any given time and "the taxonomic autonomy of language automatically compels assent to its orders when these orders are perceived as rigorously consistent" (Thiher 161). Curiously, this voluntary acceptance would seem to stem from a basic human desire for that order. Borges' kind of narrative shows that the reality we know is a human construct, that nowadays can be replaced by another suitable model. The mass media nowadays takes advantage of this fact to persuade and seduce us with more marketable models continually. Or, putting it another way, reality can only be a construct dependent on a closed system.

In "Tlön, Uqbar, Orbis Tertius," Borges suggests that perhaps reality is ordered, but according to divine laws that we do not perceive, which are, therefore, not the laws of men. (35). However, Tlön is a fictitious world designed by man, and, like our own world, or the world as we understand it, is represented according to an organized system, which therefore makes it a possible world. The suggestion is that our world, or our conception of it, is equally fictitious, a man-made labyrinth, just like Tlön (35), and leads to the conclusion that all ordered human systems, all forms of representation are closed systems which have no relation to reality or truth. That our knowledge of the world is ordered implies, in itself, that what we know is a fictitious construct. In his summaries and commentaries of works that had not yet come into existence, like that of the story, Borges virtually prescribes what many postmodernist narratives have been doing over a number of years, as well as drawing attention to underlying ideological concerns which govern the tendency towards alternative modes of composition. What Borges tells us about Tlön is a way of defamiliarizing what we ought to understand about the nature of our own world and our knowledge of it. In Tlön, the world is a heterogeneous set of independent acts, successive, temporal, but not spacial, and, as there is only "becoming," nouns do not exist (21). Moreover, the earlier allusion to Hume can, and does, take us beyond this idea to suggest that perhaps only qualities can be experienced, which is further reinforced by the fact that in the language of one hemisphere of the planet only adjectives are used. In the other, the world is a succession of mental processes that take place successively in time; to explain or judge something is an act which unites that fact to another which, in Tlön, is a posterior state of the subject which cannot affect or illuminate the previous state. Therefore, every mental state is irreducible and cannot be reduced or interpreted, which means that the act of naming or classification means falsification (23). The philosophers of Tlön know that any system simply means the subordination of everything to one single facet of the universe, and it is possible, he says, to even deny the existence of time. The present is indefinite, the past is real only as present memory and the future only exists as a present hope (24). All three exist therefore in an indefinite receding present (in Ficciones 1985: 13-36; the text has been freely paraphrased once more).

The example of Tlön draws attention to the fact that man is the creator of possible worlds which invade reality: even history and philosophy are man-made systems which invade reality in the same way. This reflects the way in which attitudes towards the relation between systems or modes of representation and reality has changed. It would appear that the nature of reality is the nature of reality as we know it. It becomes part of 
experience and is only in your head, with the consequent distortion of a mediated world. A new attitude towards time is also reflected, particularly regarding time present, and present experience is seen to be really only recent history. In Tlön, the self-less-ness of the work (which Hassan attributes to postmodernism) is also apparent as we find the idea of the single subject: all works are the works of a single author, who is atemporal and anonymous (28). Roland Barthes suggests something similar when he ascribes this quality to the "text" as distinct from the "work" (in Harari 73-81) and this idea effectively does away with plagiarism, anticipating the free interplay of texts, so that extremely stated, each text is a product of the texts that precede it. The text becomes a trace of all existing texts. In Tlön, there is only one plot with innumerable permutations and each narrative must contain its anti-narrative or it is incomplete (28).

All of these features of Tlön's ideology and literature are features of contemporary postmodernist thought and are clearly reflected in much recent narrative. They also form part of the work of Borges' contemporary Flann O'Brien, whom we mentioned earlier. In At Swim-Two-Birds he plays with what we can call the absurdity of the logic of language and discourse, the absurdity of system, where fictitious characters lead autonomous lives to the degree that they can write counter-narratives to the one they appear in. In fact, the nature of narrative, no matter how realistic on the surface, is always subject to this basic anomaly: the realistic is accepted as real, we assent to its verisimilitude, although reality always retreats when it is the subject of a narrative mode of representation. Fictional worlds, once created, no matter how arbitrarily, may become the object of research for historians and even appear in reference books. This is what happens with Tlön in Borges story, but the suggestion is that there is no real difference between fiction or fact in this respect.

All forms of representation are human constructs: any closed system, if it is coherent, is an acceptable system. We assent to it, and it is capable of invading reality, even overcoming and replacing reality. Reality gives way and recedes to be replaced by closed systems which involve the coherent play of the signifier, which is what we can call performativity. As we said, the relation between the sign and the signified has reached the stage of the free play of signifiers. In Borges' story, text books and encyclopoedias from the fictitious construct invade reality and its ideologies supercede those of "reality." But the significance of this is far-reaching. Borges writes: "10 years ago any kind of symmetry with a semblance of order was enough - dialectic materialism, anti-semitism, nazism was enough to entrance the minds of men" (in Thiher 163). And Thiher continues:

The models that knowledge proposes as the real come in a series of ruptures, one model displacing another, and each bringing about a new world. What we take to be reality at any given moment is merely a game construct, a successsful model, drawn in accord with arbitrary rules, that succeeding and more seductive models can easily replace in the minds of men if these models can impose their rules as the criteria for a successful game. (163)

This is what takes place now in contemporary society as the mass media dictated to by politics and capital continues to propagate ordered systems, realities and truths which 
postmodernism subversively shows to be fictions, sometimes by creating like systems, or by presenting alternatives. The worlds created by literature are conventional worlds, but the world we inhabit is also a conventional world where immanence, or the tendency to project or impose human structures on reality, is inevitable.

Implicit in Borges' story is the way in which one "reality" can give way readily to another: reality is malleable and we can say that it changes according to the system that is used to represent it. In literature, this idea of system can be related to genre, literary kind or mode of discourse, and, broadly speaking, we can say that reality is distorted or deformed in accordance with that mode. Changes in perspective can do something similar.

Deformation is a characteristic that can be attributed to the work of Angela Carter. Perhaps she is better known for the way in which she deconstructs fairy tales and other popular fictions in order to reconstruct them on the basis of an alternative ideology, thus contesting the ideology implicit in these stories that had previously been passively accepted. In a novel like The Infernal Desire Machines of Doctor Hoffmann, we find the gratuitous creation of systems, fictitious game constructs, which is dependent upon a kind of immanence. Immanence is the way the human mind and its structures impose themselves on and pervade reality, and inevitably means the distortion of that reality. It sometimes takes the form of anthropomorphism, which often, through various kinds of personification, tends to humanize landscapes, animals and, through religions, gods. A good example where this kind of immanence is defamiliarized is William Golding's The Inheritors. There, it is the vision of Neanderthal man, an alternative vision, and a more obviously distorted one, that is imposed on reality. In the case of Carter's novel, Hoffmann's machines allow reality to metamorphose continually in accordance with the desire of the subject: we find, therefore, a movement through pornography, the picaresque, gothic, mythology, the quest and so on at one level and, accordingly, the characters become vampires, homosexuals, hermaphrodites, or centaurs. The whole novel symbolizes the way in which modes of representation depend upon this kind of immanence and embody specific ideologies or desires. The fantastic world of this novel is the product of human fantasy as it is represented (or created) by Hollywood, television, the thriller, pornography, and gothic romance, all of which create a continually transforming landscape which is both foreign and recognizable at the same time. As we move from one world to another, characters are also transformed, change sex and race. The surface is continually in mutation in order to draw attention to the way in which reality cedes to our desires. What has been called the "imperialism of the imagination" (McHale 1987) means that reality has been subjected to and now derives from totalizing fantasies (narratives) which confront reality and very often replace it. What is suggested is that desires and fantasies invade, distort and deform reality, but more than that, it becomes clear that this is the way in which the contemporary media distort reality by catering to what are supposedly the desires of the public by providing a realism, or what we have called systems that tend towards the pornographic. In her novel, Carter installs and subverts a series of conventions for presenting reality where the "freak is the norm," suggesting that contemporary society has come to accept the distorted vision of reality that it has become accustomed to. In the novel a kind of dialectic is set up between the fantastic and the real, which can be likened to the conflict that exists nowadays between alternative systems or constructs, particularly 
in the world of politics. While the novel presents no alternative to them, it clearly underlines the fictitious nature of those systems that are represented through the explicit parody of existing modes and genres, and suggests that the creation of systems that takes place in the novel imitates what really takes place in contemporary society. The City of Infernal Desire is a place where nothing is what it seems and, in what must be a clear allusion to Borges, we are told that "life itself had become a complex labyrinth and everything that could possibly exist, did so" (1982: 11). This is the case of the novel, but it is also the case of contemporary existence.

It seems that the real has gradually become derealized. The relation between fact and fiction has become obscured, or perhaps even non-existent. We can no longer distinguish between what is true or false in terms of what is propagated by the media or any other cultural representation. We can only know conventions, forms and images, or their absence, and while we recognize them (or fail to do so) we do so conventionally, in terms of the system they embody or reflect. Because of this there can no longer be any sense of depth or significance connected to them.

Some recent fiction at least draws attention to this situation: a sense of displacement or strangeness pervades this kind of narrative because reality is strange, unfamiliar, other. Reality no longer needs to be defamiliarized because it would not be familiar even if we could possibly know it. The singularity of fictions like these is that they take us out of the familiarity of unawareness to present us with an unfamiliar system, or even a lack of system, which makes a familiar reality, or a reality that ought to be familiar, strange. This is the case of Time's Arrow by Martin Amis, where the reversal of chronology (the novel is like a video tape run backwards) brings about a similar inversion of cause and effect. The result is that the reader has to deconstruct the system imposed by the novel in order to reconstruct it in terms of real cause and effect, but with the surprising irony that we become aware of just how arbitrary and ineffectual the real system is to explain or justify the behaviour of the protagonist who was a nazi war criminal. Elsewhere, in Success, Amis shows how one of his protagonists, Gregory, an extravagent, boastful and successful character, constructs not only reality but his own personal identity out of a variety of existing models ranging from happy Dickensian boyhood scenes to explicitly pornographic (and fictitious) successes with members of both sexes. The problems for the character begin when he has to admit that his whole life is a fictitious construct which has served to put off or defer reality, which is the unpleasant truth about himself. These fictitious constructs have served as a protective casing which once removed leaves him exposed to a reality which is no longer familiar:

Everything has changed. That was all it took. A whole layer of protective casing has been ripped off my life. Nothing looks the way it used to look. Familiar objects now writhe with their own furtive being (I think they do things behind my back). When my eyes pass over the trogs, the yobs, the animals in the street - people who were hardly there at all before - I get sucked in by them and see the hell they are too. I take nothing for granted any more: the tiniest action or thought is broken down into a million contingencies. I have come out. I am one of you now. (1985: 170) 
The irony here is that nothing has changed. Once his system breaks down, the fictions no longer hold back or defer the truth with the consequence that reality is defamiliarized. More than that, we could say that reality is always an unfamiliar absence, continually deferred by the fictitious construct or system which we call knowledge.

The world as we know it is always transposed, as reality can only be known once it is framed in terms of the conventions that we already know. Derrida draws our attention to "différance" and the idea that significance is always deferred or delayed, to the extent that when we consider language, any word can be considered as the trace of all other words (in Thiher 87-90). When this is related to narrative, then each text becomes "a tissue of all other texts" (Thiher 90). Each text is made up of traces of all other texts and significance depends on its interplay with them. More simply, narrative refers not to the world but to other narrative (or other) texts, which need not imply a specific reference to an already existing text, but manifests itself in terms of tradition, genre, mode, convention and so on. Not only that, but in the same way as Robbe-Grillet explains that innovation is always regarded in terms of what it is not (1968: 183-89), we can suggest that the significance of any text, just as the significance of any word, is the result of our awareness of its relation of both similarity and difference to already existing texts. Because of this, reality is always deferred and one effect is to turn the postmodernist novel, which exploits this state of affairs, into a form of self-representation. There may be, and there usually is, overt dramatization of the work's self-referentiality, or this may be more implicit, but the postmodernist novel has moved towards a state where it has become a representation of its own coming into being with no possibility of transcendence. Roland Barthes has written:

The text ... practices the infinite deferment of the signified, is dilatory; its field is that of the signifier; it must not be conceived as "the first stage of meaning" but in complete opposition to this, as its deferred action. (1977: 158)

The text becomes a "methodological field" which signifies only in terms of play, not in terms of the "unnamable signified," so that all we know are the "disconnections, overlappings and variations" (Barthes 1977: 158) of language itself as well as those of forms of representation, which are perhaps those traces of other texts that are always there although we forget to look for them. It is in this sense that the text is a closed system which can signify only in terms of itself, and it is within the frame of this developing awareness that the postmodernist novel seeks its alternatives.

There are other areas in which the novel is becoming more self-aware also. One of these is regarding the nature of the narrative voice. There has always been an implicit separation between the narrating self and the experiencing self which has more recently been emphasized in narratological studies like those of F.K. Stanzel (1984). This suggests that whenever, even in a first person narrative, the self forms part of a narrative construct that self becomes a third person, the self becomes "other." The suggestion is that the narrative voice has become alienated from itself. The "I"is no longer "I" but a name someone gives to itself. In Beckett's The Unnamable, "I"becomes a third person. "My voice. The voice. I hardly hear it any more" (1965: 393). In Albert Angelo, B.S. Johnson 
performs an experiment with person to draw attention to the same problem - that I is not I, but the language that we speak and not the voice that speaks it. Allen Thiher calls this the schizoid separation of voice and language which, when it is dramatized gives a curious tilt to reality (131). This takes place in Martin Amis' novel Time's Arrow where the self is not one but at least two. The " $\mathrm{I}$ " of the novel is ignorant of who he is but still calls himself "T" not "he" (in fact, there is a curious alternation between first and third person which gradually begins to appear in the novel and highlights the separation). The voice comes into existence at the end of the character's life and has no awareness of the past because of which, due to the inverted chronology of the novel, each successive moment of receding time is a novelty, unfamiliar, dislodged from causal relations. The awareness of self becomes the awareness of some other. The inevitable deferment of the self is emphasized by the inverse chronology, but this also forces us to reconsider the relation between past and present and the nature of time. The description of the painted arrow on the clock at the Treblinka station suggests that time is always the same, the present, but an indefinite present. The awareness or understanding of the moment is inevitably delayed here, where an effect not unlike that of loss of memory is achieved: in the end, this effect is one of defamiliarization, as past experiences are represented from a point of view that knows them for the first time. Our understanding of the novel, like Odilo Unverdorben's understanding of his own past, is inevitably deferred.

Talking about time, and we have suggested that this is an area in which the novel continues to develop, here is an interesting quotation from $G$ by John Berger. He quotes R.G. Collingwood:

All history is contemporary history: not in the ordinary sense of the history of the comparatively recent past, but in the strict sense: the consciousness of one's own activity as one actually performs it. History is the self-knowledge of the living mind. (1985: 54)

This deferment, this "différance," also applies to time where the singularity of the moment cannot be captured. Its representation, as contemporary history is also determined and distorted by history, convention, ideology. We are distanced from, divorced from the present moment and in Time's Arrow are forced to look forward in narrative time but backward in real time in order to come to terms with or understand the present moment. The present is only understandable in terms of the past and when it is already past. G, Don Juan, in Berger's novel, tries to rediscover the presentness of the moment, the singularity of experience, through sex, although the narrative admits that only an approximation is possible in any description it may give of this singularity.

Let us consider what Martin Amis has to say on the subject:

I used to think there was no time like the present. I used to think there was no time but the present. Now I know better - or different anyway. In the end, the past will always be there. The past is all there is: the present never sticks round long enough, and the future is anybody's guess. In time, you always have to hand it to the past. It always gets you in the end. (1982: 76) 
This is the case in this novel, Other People and in Time's Arrow. The present does not exist, or rather experience is never direct, but is always deferred, as well as the past always being there to inform and to distort that present. That is, unless you happen to lose your memory, which is precisely what happens to the protagonist of Other People. Amis' reasons for this are obvious. If we always live at second hand, and if the possibilities of conventional narrative only reify this state of affairs, then the novelist has to give reality a tilt in order to make it unfamiliar and new. The tendency in this novel is to observe without understanding: everything narrative is removed from a real context; living at second hand, we only understand in terms of general explanation and respond only to the loaded significance of the word or image. In Other People, Amis tries to avoid this and make his character live at first hand. This means having no built-in memory, no received ideas, it is to be a total amnesiac. Only then, and only in fiction, is it possible to live at first hand, in the present. He writes:

Statistical evidence shows fairly conclusively that all amnesiacs are at least partially aware of what they're missing out on. They know that they do not know. They remember that they do not remember, which is a start. But that doesn't apply to her, oh no. (1982: 20)

Mary Lamb, a name pregnant with significance, lives in the present incapable of recognising even a shoe or her simplest physiological requirements. This is a new attempt to make strange, strange like the outsider, the foreigner, even in your own body, the inhabitant of a foreign country, which might as well be another planet, where you do not know the rules or the system, although the inevitable gradually takes place, and knowledge, the cultural baggage returns. Mary realizes she is other: Amy Hide, the protagonist's double, whom she has been searching for, turns out to be herself. The point would seem to be that in order to know the self, we become the object of our own recent history, we become a third person, we become other people.

Up to now we have observed that the novel continues to be concerned with realism, although to be realistic is to understand that there is a clear distinction between reality and experience and our knowledge and understanding of them. The development of the novel towards postmodernism reflects this awareness and finds itself continually seeking the defamiliarization of the fictitious constructs that represent a reality that recedes into absence in order to admit them. As oppositional discourse, the novel continues to set itself up in opposition to existing realisms and to search for alternative modes of composition or strategies which draw attention to the immanences which impose a fictitious order on experience. We have already observed how Borges anticipates many of these concerns in his short stories, which envisage fictions of this kind. We also noted that postmodernity is also a post-Einsteinian world which entails new ways of conceptualizing time. Borges considers this in his "El jardin de senderos que se bifurcan" ("The Garden of Forking Paths"), and while he contests conventional attitudes towards time, he also reflects a developing awareness that time is both complex and variable. Firstly, Yu Tsun, believing he is going to die reflects that "all things happen to one precisely now. Centuries and centuries and only in the present do events occur, innumerable men in the air, on land and 
at sea, and everything that really happens happens to me" (1985: 102; again the translation is my own). Again the emphasis is on the fact that only the present moment exists, that the past only exists as part of the present and all experience culminates in the subjective here and now. However, when Yu Tsun discovers that the labyrinth he seeks, the garden of forking paths, involves a bifurcation in time and not in space, this attitude develops even further:

In all fiction, each time a man confronts a variety of alternatives, he chooses one and eliminates the others; in that of the almost inextricable Ts'ui Pên, he opts, simultaneously, for all of them. He creates in this way several futures, several times which also proliferate and bifurcate. (111-2, my translation)

This clearly contests the idea of the single structure and the feeling of inevitability that the traditional novel depends upon for its sense of verisimilitude and it is precisely this kind of plurality that we find in Amis' Other People. This novel ends as it begins. repeating the very same opening in order to suggets how the same plot might be, or even must be, reworked in any number of ways. Remember, the author can only construct possibilities and these are multiple.

In a similar vein, Borges' story of Tlön begins by telling us that mirrors are monstrous because they multiply the number of men. Angela Carter's novel of Dr. Hoffman provides us with "reflections in broken mirrors" and it is monstrous because it multiplies the number of versions of reality and the immanences which lead to infinite distortions. The present moment, like time and reality itself, is multiple.

It might be considered that the novel is simply playing with possibility in this regard but these narratives reflect a real awareness that the conventional conception of time is inadequate. The point is that man-made ordered systems are either fictitious or give only a partial vision of the truth. They fail to consider that time is variable, and not only because of the way it changes subjectively. In The Child in Time, Ian McEwan offers a variety of subjective appreciations of the passage of time ranging from the slowed down time experienced during a car crash to a mystical experience that puts together simultaneously events that took place many years apart. As well as representing them as part of the narrative, there is a didactic passage which involves a discussion between the protagonist and a friend of his, who is a physicist. A few extracts from what Thelma tells Stephen Lewis are enlightening:

Whatever time is, the commonsense, everyday version of it as linear, regular, absolute, from left to right, from past right through the present to the future, is either nonsense or a tiny fraction of the truth. ... Time is variable. We know it from Einstein .... In relativity theory time is dependent on the speed of the observer. What are simultaneous events to one person can appear in sequence to another. There's no absolute, generally recognised "now." (117-18)

It is probable that there is a higher order of reality which we do not yet understand, an order that "could begin to take subjective experience into account" (120) and explain 
the mystic's experience of timelessness, the chaotic unfolding of time in dreams, the Christian moment of fulfilment and redemption, the annihilated time of deep sleep, the elaborate time schemes of novelists, poets, daydreamers, the infinite unchanging time of childhood...

... the slow time of panic. (120)

The limitations of conventional modes of representation and their nature as fictitious systems of order is clearly suggested here, but at the same time narrative itself is able to offer alternative strategies which draw attention to or allude to a reality which conventional systems are unable to represent.

Perhaps one of the most striking things is the sense of strangeness or even foreignness that pervades some of the works we have mentioned. We are literally taken into another world where we discover other people, although, ironically, it turns out that these other people are ourselves, and that our world is other than what we believe it to be. Amis and Carter are like many authors who tilt reality in order to further the necessary process of defamiliarization. In spite of the naturalization of many of its strategies the postmodernist novel continues to contest not only conventional, but even unconventional ways of seeing in such a way that we reconsider the efficacy of existing modes of representation.

To transgress the rules, to go beyond the limits of the single structure, to modify the uses of categories of discourse, particularly with regard to time, voice and perspective, is where the postmodernist novel is able to seek alternatives and continue its development regarding the possibilities for the defamiliarization of ways of representing reality. However, while it sets itself up in opposition to existing modes of presentation in its search for alternatives, the inherent scepticism of the postmodernist novel forbids it from giving authority to any, resigning itself to the consideration of reality as an inevitable, and perhaps irretrievable, absence.

Rewriting history (perhaps in $101 / 2$ chapters), dislocating time and voices, deforming the real, highlighting the absurdity of logic and system, defamiliarizing the intermediary role of narrative and exaggerating the immanence that projects and imposes human desires and structures on reality, these are only some of the alternatives of this oppositional discourse of unbelief which draws attention to the fictitious nature of the real.

\section{Works Cited}

Alter, Robert. Partial Magic: The Novel as a Self-Conscious Genre. Berkeley: U. of California Press, 1975.

Attridge, Derek, Nigel Fabb, Alan Durant and Colin MacCabe, eds. The Linguistics of Writing.

Arguments Between Language and Literature. Manchester: Manchester U.P., 1987.

Amis, Martin. Other People. Harmondsworth: Penguin, 1982.

. Success. Harmondsworth: Penguin, 1985.

Time's Arrow. Harmondsworth: Penguin, 1992.

Bakhtin, M. "Epic and Novel." 1981 5-38.

The Dialogic Imagination: Four Essays. Ed. Michael Holquist. Trans. Caryl Emerson \& Michael Holquist. Austin and London: U. of Texas Press, 1981. 
Barthes, Roland. Images-Music-Text. Trans. Stephen Heath. New York: Hill \& Wang, 1977. "From Word to Text." Harari 73-81.

Beckett, Samuel. Three Novels. New York: Grove Press, 1965

Berger, John. G. London: Chatto \& Windus, 1985.

Borges, Jorge Luis. Ficciones. Barcelona: Planeta-Agostini, 1985.

. "El jardin de senderos que se bifurcan." 1985 101-16.

"Tlön, Uqbar, Orbis Tertius." 1985 13-36.

Bradbury, Malcolm. Possibilities. Essays on the State of the Novel. London: Oxford U. P., 1977.

Calderwood, James L. and Harold E. Toliver, eds. Perspectives on Fiction. New York: Oxford U.P., 1968.

Calinescu, Matei. Five Faces of Modernity. Durham: Duke U.P., 1987.

Calinescu, Matei and Douwe Fokkema, eds. Exploring Postmodernism. Amsterdam and Philadelphia: John Benjamins, 1987.

Carter, Angela. The Infernal Desire Machines of Doctor Hoffman. Harmondsworth: Penguin, 1982.

Genette, Gerard. "The Frontiers of Narrative." Figures of Literary Discourse. Trans. Alan Sheridan. Introd. M.R. Logan. London: Blackwell, 1982, 127-44.

Golding, William. The Inheritors. London: Faber and Faber, 1961.

Harari, Josué, ed. Textual Strategies. Perspectives in Poststructuralist Criticism. London: Methuen, 1980.

Hassan, Ihab. "Pluralism in Postmodernist Perspective." Calinescu and Fokkema 18-23.

Holquist, Michael and Walter R. Reed. "Six These on the Novel and some Metaphors." New Literary History. 11 (1988): 413-23.

Hutcheon, Linda. Narcassistic Narrative. The Metafictional Paradox. London: Methuen, 1984. . The Politics of Postmodernism. London: Routledge, 1989.

Jameson, Frederic. "Reading without Interpretation: Postmodernism and the Video Text." Attridge et al. 198-223.

Johnson, B.S. Arent You Rather Young to be Writing Your Memoirs. London: Hutchinson, 1973. Albert Angelo. New York: New Directions, 1987.

Lemon, Lee T. and Marion J. Reis, eds. Russian Formalist Criticism: Four Essays. Lincoln: University of Nebraska Press, 1965.

Lodge, David. The Modes of Modern Writing: Metaphor and Metonymy and the Typology of Modern Literature. London: Edward Arnold, 1977.

Lyotard, Jean François. The Postmodern Condition. A Report on Knowledge. Trans. Geoff.

Bennington and Brian Massumi. Manchester: Manchester U.P., 1984.

McEwan, Ian. The Child in Time. London: Picador, 1988.

McHale, Brian. Postmodernist Fiction. New York and London: Methuen, 1987.

O'Brien, Flann. At Swim-Two-Birds. Harmondsworth: Penguin, 1967.

Robbe-Grillet, Alain. "Old 'Values' and the New Novel." Calderwood and Toliver 183-189.

Shklovsky, Viktor. "Art as Technique." Lemon and Reis 1965 5-24.

Stanzel, F.K. A Theory of Narrative. Trans. Charlotte Geodiche. Cambridge: C.U.P., 1984.

Stevenson, Randall. Modernist Fiction. An Introduction. Hemel Hempstead: Harvester Wheatsheaf, 1992.

Thiher, Allen. Words in Reflection: Modern Language Theory and Postmodernist Fiction. Chicago \& London: U.Chicago Press, 1985.

Waugh, Patricia. Metafiction. The Theory and Practice of Self-Conscious Fiction. London and New York: Methuen, 1984. 